\title{
Aa.Vv., Un exotisme littéraire médiéval? Actes du colloque du Centre d'Études Médiévales et Dialectales de Lille 3, 6-7 octobre 2006
}

\section{Maria Colombo Timelli}

\section{(2) OpenEdition}

\section{Journals}

Édition électronique

URL : http://journals.openedition.org/studifrancesi/7454

DOI : 10.4000/studifrancesi.7454

ISSN : 2421-5856

Éditeur

Rosenberg \& Sellier

\section{Édition imprimée}

Date de publication : 1 décembre 2009

Pagination : 597

ISSN : 0039-2944

\section{Référence électronique}

Maria Colombo Timelli, «Aa.Vv., Un exotisme littéraire médiéval? Actes du colloque du Centre d'Études Médiévales et Dialectales de Lille 3, 6-7 octobre 2006 », Studi Francesi [En ligne], 159 (LIII | III) | 2009, mis en ligne le 30 novembre 2015, consulté le 09 janvier 2021. URL : http://journals.openedition.org/ studifrancesi/7454; DOI : https://doi.org/10.4000/studifrancesi.7454

Ce document a été généré automatiquement le 9 janvier 2021.

\section{c)}

Studi Francesi è distribuita con Licenza Creative Commons Attribuzione - Non commerciale - Non opere derivate 4.0 Internazionale. 


\title{
Aa.Vv., Un exotisme littéraire médiéval? Actes du colloque du Centre d'Études Médiévales et Dialectales de Lille 3, 6-7 octobre 2006
}

\author{
Maria Colombo Timelli
}

\section{RÉFÉRENCE}

Un exotisme littéraire médiéval? Actes du colloque du Centre d'Études Médiévales et Dialectales de Lille 3, 6-7 octobre 2006, «Bien dire et bien aprandre. Revue de Médiévistique», 26, 2008.

1 Les mots mêmes exotique et exotisme n'existant pas en français médiéval (l'adjectif remonte à Rabelais, alors que le substantif est encore plus récent, du XIX ${ }^{\mathrm{e}}$ siècle), il est indispensable, comme le fait Catherine GAULLIER-BOUGASSAS dans un article introductif, de s'interroger sur l'existence de la notion d'exotisme au Moyen Âge et sur ses rapports avec celle de merveilleux. Elle relève ainsi que, entre $\mathrm{XII}^{\mathrm{e}}$ et $\mathrm{XIII}^{\mathrm{e}}$ siècle, textes encyclopédiques, récits de voyage, chroniques et textes littéraires témoignent tous de la présence d'un exotisme dont la constante est cependant de rassurer et de confirmer l'ethnocentrisme occidental et chrétien (Un exotisme littéraire médiéval?, pp. 7-20).

2 Les contributions sont organisées selon quatre axes: une première section est consacrée aux «Poèmes épiques et altérité sarrasine».

Gérard GROS, Présentation et mort d'un personnage: Chernubles de Muneigre dans la 'Chanson de Roland', pp. 23-38. Chevelu et vigoureux, provenant d'un pays infernal mais portant un équipement rehaussé d'escarboucles, Chernuble est un personnage «estrange» au double sens du terme, qui sera tué par Roland lui-même. 
Magali JANET (Exotismes de la parure et du dépouillement de la "Chanson d'Antioche" à la "Chanson de Jérusalem", pp. 39-54) analyse deux types d'exotisme dans le premier cycle de la Croisade: l'exotisme «attendu» des coutumes des Sarrasins, qui peut glisser vers la merveille, et la nudité et travestissement des Tafurs, exotisme «à rebours» celui-ci, selon la définition d'E. Baumgartner, situé au sein des troupes mêmes des Croisés.

Armelle LECLERCQ (L'Orient monstrueux dans le premier Cycle de la Croisade, pp. 55-67) montre la co-présence dans ces chansons épiques de détails réels (peuples, montures, climat, interprètes) et de phénomènes merveilleux (tentes, automates, monstres); le combat contre le dragon dans les Chétifs, en particulier, remplace les batailles réelles de la Croisade et fait de ses vainqueurs de nouveaux saints.

Wilfrid BESNARDEAU, Les Infidèles dans l'“'Estoire de la guerre sainte" d'Ambroise, pp. 69-80. Relation en vers de la troisième Croisade, l'Estoire (fin du XII siècle) est un heureux compromis: récit vraisemblable, sinon réaliste, il intègre néanmoins, pour désigner ou décrire les Infidèles, des éléments tirés tant de l'épopée que du roman contemporains.

7 Les textes non littéraires offrent bien naturellement des témoignages précieux pour appréhender la notion même d'exotisme à l'époque médiévale: c'est donc à ceux-ci qu'est réservée une deuxième partie («Encyclopédies, chroniques et récits de pèlerinage: la curiosité pour les 'mirabilia' et la peur des monstruosités»).

8 Selon Bernard RiBÉmont (La licorne, un animal exotique? pp. 99-119), la littérature encyclopédique médiévale en langue française (Brunetto Latini et Jean Corbechon) impose une sorte de "vulgate» qui réduit l'exotisme de l'unicorne et le rapporte essentiellement à un rite de chasse.

9 Philippe HAUGEARD, L'expérience de l'altérité dans la "Vie de saint Louis" de Joinville, pp. 121-135. Joinville ne commente pas explicitement les usages des Bédouins, Mongols et Comans, sa condamnation se fondant plutôt sur la connivence culturelle qu'il établit avec ses lecteurs. Pour l'historien de saint Louis, le véritable danger réside dans l'attraction et la contagion que le monde arabo-musulman peut toujours exercer sur les Chrétiens.

leine CASTELLANI (Bédouins, Tartares et Assassins, les figures de l'Autre oriental, pp. 137-149) revient sur le même texte: dans les descriptions des usages de ces trois peuples, Joinville témoigne de l'ambiguïté de l'Orient, aussi fascinant que dangereux, dans une vision qu'il partage avec ses contemporains, entre autres Jacques de Vitry, et qui est destinée à une longue fortune.

11 Une troisième section porte sur les «Espaces exotiques dans le roman médiéval».

12 Aimé PETIT (Carthage, ville exotique dans le "Roman d'Enéas", pp. 199-211) met l'accent sur les différences entre la description de Carthage qui se lit dans le manuscrit $A$, où c'est le merveilleux qui l'emporte, et celle qui se trouve dans le manuscrit $D$, où l'image de la ville est associée au portrait de Didon, reine magnifique et séduisante, représentant l'exotisme amoureux.

13 Florence tanNiou (De l'Orient rêvé à l'Orient révélé: les mutations de l'exotisme du "Roman de Troie" de Benoît de Sainte-Maure au "Roman de Troie en prose" (Prose 1), pp. 211-226) souligne la disparition de l'exotisme de Benoît dans la réécriture en prose; le prosateur actualise sa source sur le plan géographique et historique, assume un projet didactique et moralisateur, et soumet l'Orient de la source à la perception chrétienne. 
14 La dernière section porte un titre captivant: «Curieux et si divers usages de l'Autre: l'Autre et le Même».

15 L'approche d'Anne B. DARMSTÄTTER au Jeu de saint Nicolas se situe sur un plan religieux (Émirs, saints et buveurs. Altérité et réalité dans le "Jeu de saint Nicolas" de Jean Bodel, pp. 271-286). Représentant d'une vision chrétienne du monde influencée par le néoplatonisme, Jean Bodel adapterait les personnages et les milieux de sa pièce, notamment la taverne, dans le but de consolider son identité et son appartenance à une collectivité forte d'une longue tradition et fondée sur les valeurs sûres du christianisme.

16 Caroline cazanave (Trajets exotiques dans la tradition des "Huon de Bordeaux": de la chanson de geste à l'opéra, pp. 287-307). Si la couleur locale orientale est toujours présente, elle évolue évidemment de la chanson de geste du XIII ${ }^{e}$ siècle à la prose du $\mathrm{Xv}^{\mathrm{e}}$, et surtout dans les réfections de Tressan (Bibliothèque Universelle des Romans, 1778), dans l'œuvre de Wieland (1780) et dans les livrets d'opéra des décennies suivantes. On passe ainsi de la valeur symbolique de l'Orient à une préoccupation plus réaliste en époque moderne, de la vision auto-référentielle propre au Moyen Âge à des données plus vérifiables, quasi documentaires, même si l'Orientalisme des $\mathrm{XVIII}^{\mathrm{e}}$-XIX ${ }^{\mathrm{e}}$ siècles demeure, en partie au moins, encore fortement fantasmatique. 